EDITOR'S

\title{
Systematic review of studies comparing combined treatment with paracetamol and ibuprofen, with either drug alone
}

\author{
Edward Purssell
}

\section{Correspondence to}

Edward Purssell, Department of Primary and Intermediate

Care, King's College London, James Clerk Maxwell Building,

57 Waterloo Road, London SE1 8WA, UK; edward.purssell@kcl.ac.uk

Accepted 21 July 2011 Published Online First 24 August 2011

\begin{abstract}
Objective To evaluate the evidence surrounding the use of combinations of paracetamol and ibuprofen in the treatment of fever.

Design Systematic narrative review of randomised controlled trials using the UK Economic and Social Research Council guidance on the conduct of narrative synthesis.
\end{abstract}

Setting Inpatient, outpatient and home care.

Patients Children with fever.

Main outcome measures The effect of combination treatments of paracetamol and ibuprofen on fever and comfort, and identification of side effects.

Results Seven studies were identified, six of which provided useful data for the evaluation of the effect of treatment on temperature. Overall these studies showed limited benefit from the combined treatment until around $4 \mathrm{~h}$, after which there was a statistically but only marginally clinically significant benefit. Two studies contained data directly relating to comfort; these suggest a marginal benefit from the combined treatment, but the clinical significance of this was limited. There was no evidence of greater side effects or toxicities associated with the combined treatment. However, it is important to note that these studies were small, short term, and not conducted in the normal setting in which these treatments are given.

Conclusions There is little evidence of any benefit or harm from the combined treatment compared with the use of each drug alone. In the absence of such benefit, there is little to recommend the unnecessary use of polypharmaceutical methods to treat a symptom that does not require treatment, when effective monotherapies exist.

\section{INTRODUCTION}

Fever is a common symptom which consistently causes high levels of anxiety in parents and professionals alike, leading to the widespread and often unnecessary use of antipyretic medications. ${ }^{1}{ }^{2}$ Although paracetamol and ibuprofen on their own are effective, safe and relatively inexpensive antipyretic drugs, some clinicians are known to recommend combining the two drugs, despite the lack of recommendations to this effect. ${ }^{3}$

Recent guidelines from the American Academy of Pediatrics have noted the lack of evidence for this practice, but in recognising that this is a common occurrence they suggest that those who advise or prescribe this treatment ensure carers understand the formulation and dosage, and stress that the primary aim of the treatment is to improve the child's comfort rather than to

\section{What is known on this subject?}

- Fever is a common symptom and, while it may be indicative of serious disease, is not dangerous in itself.

- Parents and professionals often treat this symptom with a combination of paracetamol and ibuprofen, despite the lack of official guidance to this effect.

\section{What this study adds}

- A systematic review of randomised controlled trials comparing combinations of paracetamol and ibuprofen to each drug alone, combined with expert opinion in the form of official guidelines.

- Only marginal benefit was shown for the combined treatments compared with each drug individually, which taken alongside the risk of overdose and further increasing the fear of fever, suggests that there is little to recommend this practice.

reduce temperature. ${ }^{4}$ This narrative systematic review aims to collate and critique the evidence surrounding the practice of combining paracetamol and ibuprofen, using the principles underlying the UK Economic and Social Research Council guidance on the conduct of narrative synthesis ${ }^{5}$ and the Preferred Reporting Items for Systematic Reviews and Meta-Analyses (PRISMA) statement. ${ }^{6}$

\section{METHODS}

A systematic literature search was carried out in May 2011 to identify studies comparing the efficacy or effectiveness of any dose of a combination of paracetamol and ibuprofen, either together or separately, with either drug alone. Outcome measures were the effect on temperature, comfort and the occurrence of any side effects or toxicities. Medline (1948-May 2011) and Embase (1980-May 2011) were searched using the keywords ibuprofen; paracetamol; acetaminophen and antipyretic. Trade names were not searched. In addition to the database search, hand searching was done of the references from the UK National Institute for Health and Clinical Excellence (NICE) guidelines on the treatment of fever in children under 
the age of 5 years $^{7}$ and the American Academy of Pediatrics guidelines on fever and antipyretic use in children. ${ }^{4}$

Inclusion criteria were that studies should be randomised controlled trials with data on any of the three outcomes. For practical reasons, literature was restricted to English language; this is acknowledged as a limitation since the author is aware that combination products are in use in some nonEnglish-speaking countries, although not licensed for use in the European Union. Study quality was assessed using the CONSORT statement for the reporting of pragmatic trials to assess the risk of bias. ${ }^{8}$ Additionally, expert opinion was established by examining official recommendations from professional or similar organisations.

\section{RESULTS}

Seven studies were retrieved and screened, all of which met the inclusion criteria and were therefore included in the review. Details of these are shown in table 1.9-15 The CONSORT scores ranged from 17 to 22 out of 22 , and all studies were included in at least one part of the analysis. Although one study contained no extractable numerical temperature data, it did include useful laboratory values, and the findings are included in the analysis of safety only. This paper also had the lowest CONSORT score. ${ }^{9}$ Six of the studies contained useful data about temperature response to combination treatment, albeit in different and non-directly combinable forms; two studies contained data on comfort; and three had sufficient follow-up time to detect side effects and toxicities. Details of how significant temperatures were defined in the studies are shown in table 2. Data were extracted onto a standard template by one reviewer on two separate occasions.

\section{TREATMENTS}

There were a variety of dosages and timings making direct comparison difficult. Experimental groups in the studies used a variety of combinations, including a single combined dose of both drugs ${ }^{14}$; a single dose of each drug but which were separated by $3^{12} 15$ or $4 \mathrm{~h}^{13}$; or multiple combined ${ }^{9}$ or alternating doses. ${ }^{10} 11$ Doses of paracetamol and ibuprofen also varied from 12.5 to $15 \mathrm{mg} / \mathrm{kg}$ and 5 to $10 \mathrm{mg} / \mathrm{kg}$ respectively; no dosage adjustments were made for the combination treatments. There were similar differences in dosing intervals, with paracetamol being given 4-6 hourly and ibuprofen 6-8 hourly. Within these studies there are therefore a multitude of different treatment approaches, and although they fall into two main categories, namely combined or alternating doses, there are insufficient data to treat them as separate treatments.

\section{EFFECT ON TEMPERATURE}

The primary outcome measure of all studies was the effect of the treatment on temperature. Again they fell into two broad categories: those that looked primarily at the shortterm effects, that is under $8 \mathrm{~h}$; and those that took a longer view. Details of the outcomes are shown in table 3 . No studies reporting temperature decline as a primary outcome showed a difference between combined and individual treatments within the first $3 \mathrm{~h}$, however by $4 \mathrm{~h}$ a consistent difference did occur. In one study comparing a combined treatment and paracetamol the difference was $0.6^{\circ} \mathrm{C}$ at $4 \mathrm{~h}(\mathrm{p}=0.05)$ and $0.8^{\circ} \mathrm{C}$ at $5 \mathrm{~h}(\mathrm{p}=0.003)$, but this had fallen to $0.1^{\circ} \mathrm{C}$ by $6 \mathrm{~h}^{12}$. The other study reporting these data found that both a single combined dose, and a single alternating dose were superior to ibuprofen alone at 4, 5 and $6 \mathrm{~h}$. At $4 \mathrm{~h}$ the difference between both

Table 1 Study characteristics

\begin{tabular}{|c|c|c|c|c|}
\hline Study & Interventions & Temperature & Age & Follow-up time \\
\hline Lal et $a l^{9 *}$ & $\begin{array}{l}\text { G1: paracetamol } 10 \mathrm{mg} / \mathrm{kg} 8 \text { hourly, } \mathrm{n}=33 \\
\text { G3: paracetamol } 10 \mathrm{mg} / \mathrm{kg} \text { and ibuprofen } 10 \mathrm{mg} / \mathrm{kg} \\
8 \text { hourly, } \mathrm{n}=18\end{array}$ & $>38.5^{\circ} \mathrm{C}$ axilla & $\begin{array}{l}\text { Mean }(95 \% \mathrm{CI}) 2.85 \text { years } \\
(1.75 \text { to } 3.95) \text { and } 3.02 \\
(2.34 \text { to } 3.7)\end{array}$ & 5 days \\
\hline Erlewyn-Lajeunesse et al ${ }^{14}$ & $\begin{array}{l}\text { G1: paracetamol } 15 \mathrm{mg} / \mathrm{kg} \text { single dose, } \mathrm{n}=37 \\
\mathrm{G} 2 \text { : ibuprofen } 5 \mathrm{mg} / \mathrm{kg} \text { single dose, } \mathrm{n}=35 \\
\mathrm{G} 3 \text { : paracetamol } 15 \mathrm{mg} / \mathrm{kg} \text { and ibuprofen } 5 \mathrm{mg} / \mathrm{kg} \\
\text { single dose, } \mathrm{n}=36\end{array}$ & $\geq 38^{\circ} \mathrm{C}$ tympanic & 6 months -10 years & $2 \mathrm{~h}$ \\
\hline Nabulsi et a/ ${ }^{13}$ & $\begin{array}{l}\text { G2: ibuprofen } 10 \mathrm{mg} / \mathrm{kg} \text {, followed by placebo at } 4 \mathrm{~h} \text {, } \\
\mathrm{n}=33 \\
\mathrm{G} 3 \text { : ibuprofen } 10 \mathrm{mg} / \mathrm{kg} \text {, followed by paracetamol } \\
15 \mathrm{mg} / \mathrm{kg} \text { at } 4 \mathrm{~h}, \mathrm{n}=36\end{array}$ & $\geq 38.8^{\circ} \mathrm{C}$ rectal & 6 months -14 years & $8 \mathrm{~h}$ \\
\hline Sarrell et $a l^{11 \dagger}$ & $\begin{array}{l}\text { G1: paracetamol } 12.5 \mathrm{mg} / \mathrm{kg} 6 \text { hourly, } \mathrm{n}=154 \\
\mathrm{G} 2 \text { : ibuprofen } 5 \mathrm{mg} / \mathrm{kg} 8 \text { hourly, } \mathrm{n}=155 \\
\text { G3: paracetamol } 12.5 \mathrm{mg} / \mathrm{kg} \text { alternately with ibupro- } \\
\text { fen } 5 \mathrm{mg} / \mathrm{kg} 4 \text { hourly, } \mathrm{n}=155\end{array}$ & $\geq 38.4^{\circ} \mathrm{C}$ rectal & 6 months -3 years & 10 days \\
\hline Hay et $a l^{10}$ & $\begin{array}{l}\text { G1: paracetamol } 15 \mathrm{mg} / \mathrm{kg} 4-6 \text { hourly, } \mathrm{n}=52 \\
\text { G2: ibuprofen } 10 \mathrm{mg} / \mathrm{kg} 6-8 \text { hourly, } \mathrm{n}=52 \\
\mathrm{G} 3 \text { : paracetamol } 15 \mathrm{mg} / \mathrm{kg} 4-6 \text { hourly and ibuprofen } \\
10 \mathrm{mg} / \mathrm{kg} 6-8 \text { hourly, } \mathrm{n}=52\end{array}$ & $37.8-41^{\circ} \mathrm{C}$ axilla & 6 months -6 years & 5 days \\
\hline Kramer et al ${ }^{12}$ & $\begin{array}{l}\text { G1: paracetamol } 15 \mathrm{mg} / \mathrm{kg} \text { followed by placebo at } 3 \mathrm{~h} \\
\text { and paracetamol } 15 \mathrm{mg} / \mathrm{kg} \text { at } 4 \mathrm{~h}, \mathrm{n}=19 \\
\text { G3: paracetamol } 15 \mathrm{mg} / \mathrm{kg} \text { followed by ibuprofen } \\
10 \mathrm{mg} / \mathrm{kg} \text { at } 3 \mathrm{~h} \text { and placebo at } 4 \mathrm{~h}, \mathrm{n}=19\end{array}$ & $\begin{array}{l}>38^{\circ} \mathrm{C} \text { oral } \\
\text { (rectal }<2 \text { years) }\end{array}$ & 6 months -6 years & $24 \mathrm{~h}$ \\
\hline Paul et a/15 & $\begin{array}{l}\text { G1: ibuprofen } 10 \mathrm{mg} / \mathrm{kg} \text { followed by paracetamol } \\
15 \mathrm{mg} / \mathrm{kg} \text { at } 3 \mathrm{~h}, \mathrm{n}=20 \\
\mathrm{G} 2 \text { : ibuprofen } 10 \mathrm{mg} / \mathrm{kg} \\
\text { G3: ibuprofen } 10 \mathrm{mg} / \mathrm{kg} \text { and paracetamol } 15 \mathrm{mg} / \mathrm{kg}\end{array}$ & $>38^{\circ} \mathrm{C}$ temporal artery & 6 months -6 years & $6 \mathrm{~h}$ \\
\hline
\end{tabular}

*This study also included a nimesulide arm not analysed here.

${ }^{\dagger} \mathrm{Half}$ of each group were initially loaded with paracetamol and ibuprofen; because there was no difference these were analysed together. 
combined treatments and ibuprofen was $0.6^{\circ} \mathrm{C}(\mathrm{p}=0.002)$, at 5 and $6 \mathrm{~h}$ the difference was $1.1^{\circ} \mathrm{C}$ and $1.3^{\circ} \mathrm{C}$ for the single dose, and $1.2^{\circ} \mathrm{C}$ and $1.6^{\circ} \mathrm{C}$ for the alternate dose respectively $(\mathrm{p}<0.001) .{ }^{15}$

An alternative view of effectiveness is to study the number who were afebrile at different time points. The percentage achieving this was similar at $6 \mathrm{~h}$, but at 7 and $8 \mathrm{~h}$ more children were afebrile in the combined than the ibuprofen group, the difference being $40.9 \%$ at $7 \mathrm{~h}$ and $45.1 \%$ at $8 \mathrm{~h}$ $(\mathrm{p}<0.001)$, although the maximum temperature decline was similar at $2.2^{\circ} \mathrm{C}$ and $2.1^{\circ} \mathrm{C}$ in the combined and ibuprofen groups respectively. ${ }^{13}$ One study did suggest a faster rate of fall in the combined group compared with individual drugs, with the percentages having a temperature $>37.2^{\circ} \mathrm{C}$ being $36 \%$ for paracetamol, $15 \%$ for ibuprofen and $9 \%$ for the combined

Table 2 Definitions of significant temperature

\begin{tabular}{ll}
\hline Study & Definitions \\
\hline Erlewyn-Lajeunesse et $a l^{14}$ & Difference of $1^{\circ} \mathrm{C}$ at $1 \mathrm{~h}$ clinically significant \\
Nabulsi et $a l^{13}$ & Normal temperature $36.5-37.9^{\circ} \mathrm{C}$ \\
Sarrell et $a l^{11}$ & Afebrile if $<37.8^{\circ} \mathrm{C}$ \\
Hay et $a l^{10}$ & Time without fever $<37.2^{\circ} \mathrm{C}$ \\
Kramer et $a l^{12}$ & Fever if $>38^{\circ} \mathrm{C}$ \\
Paul et a $l^{15}$ & $38^{\circ} \mathrm{C}$ standard temperature threshold used by \\
& schools and day-care for exclusion \\
\hline
\end{tabular}

treatments at $2 \mathrm{~h}$, the equivalent figures for $4 \mathrm{~h}$ being $29 \%$, $15 \%$ and $2 \%$ respectively. ${ }^{10}$

There were two studies that looked at longer-term outcomes, albeit in different forms. One found that those in the combined group had more time without fever in the first $24 \mathrm{~h}$ than both those receiving paracetamol or ibuprofen alone, however this was only statistically significant compared with paracetamol, the difference being $277.1 \mathrm{~min}(\mathrm{p}<0.001)$, while that for ibuprofen was $162.2 \mathrm{~min}(\mathrm{p}=0.2) .{ }^{10}$ Maximum recorded daily temperatures also differed among treatments, while there was no difference between paracetamol and ibuprofen: on days 1-3 the combined treatment led to a lower maximum temperature of $0.91^{\circ} \mathrm{C}, 0.96^{\circ} \mathrm{C}$ and $0.8^{\circ} \mathrm{C}$ compared with paracetamol alone, and $0.96^{\circ} \mathrm{C}, 0.88^{\circ} \mathrm{C}$ and $1.11^{\circ} \mathrm{C}$ compared with ibuprofen (all $\mathrm{p}<0.001) .{ }^{11}$

\section{EFFECT ON DISCOMFORT AND SIDE EFFECTS}

Two studies looked at discomfort, one asking parents about discomfort at $24 \mathrm{~h}, 48 \mathrm{~h}$ and at 5 days, ${ }^{10}$ the other asking parents to assess their child using the non-communicating children's pain checklist. ${ }^{11}$ In the first of these there was no significant difference between treatments, at $24 \mathrm{~h}$ : $44 \%$ of the paracetamol children were without discomfort compared with $69 \%$ in the ibuprofen and $56 \%$ in the combined groups. For $48 \mathrm{~h}$ this was $65 \%, 71 \%$ and $69 \%$; and at 5 days $88 \%, 61 \%$ and $76 \%$ respectively. In the latter study paracetamol was superior

Table 3 Summary of outcome measures

\begin{tabular}{|c|c|c|c|}
\hline Study & Temperature & Side effects & Comfort \\
\hline Lal et $a /^{9}$ & Insufficient data & $\begin{array}{l}\text { Slightly raised SGPT, SGOT, urea and creati- } \\
\text { nine in mixed group. No clinical significance }\end{array}$ & No data \\
\hline Erlewyn-Lajeunesse et al ${ }^{14}$ & $\begin{array}{l}\text { Mean fall over } 1 \mathbf{h}^{\circ} \mathbf{C}(\mathbf{t}) \text { No clinically or statisti- } \\
\text { cally significant difference }\end{array}$ & No data & No data \\
\hline
\end{tabular}

No serious adverse reactions. No sign of Gl, hepatic, renal toxicity

\section{P 0.95, I 0.92, PI 1.22}

Nabulsi et al ${ }^{13}$

$\%$ Afebrile at 6-8 $\mathbf{h}(\mathbf{r})$ greater in mixed group

$6 \mathrm{~h}:$ I 57.6, PI 83.3, $\mathrm{p}=0.018$

$7 \mathrm{~h}:$ I 45.2, PI 86.1, $\mathrm{p}<0.001$

$8 \mathrm{~h}: \mid 35.5, \mathrm{PI} 80.6, \mathrm{p}<0.001$

Max temperature decline no difference

Sarrell et al ${ }^{11} \quad$ Mean max temperature on days $1-3{ }^{\circ} \mathrm{C}(\mathbf{r})$ lowest in mixed group, highest in paracetamol 1 day: $P$ 40.6, I 40.6, PI $39.6 p<0.001$

2 day: $P$ 39.7, I 39.7, PI $38.8 \mathrm{p}<0.001$

3 day: $P$ 39.3, I 39.6, PI $38.5 p<0.001$

Hay et $a l^{10} \quad$ Minutes without feverfirst $4 \mathbf{~ h}(\mathbf{a})$ : greatest in mixed group, shortest in paracetamol group

P 116.2, I 156, PI 171.1

Pairwise comparisonmixed vs paracetamol $p<0.001$, ibuprofen vs paracetamol $p=0.001$

First 24 h: same pattern

P 940.3, PI 1055.2, PI 1217.4

Kramer et $a l^{12}$ Mean temperature at 3-6 $\mathrm{h}{ }^{\circ} \mathrm{C}(\mathrm{o} / \mathrm{r})$ no difference at 3 or $6 \mathrm{~h}$, at 4 and $5 \mathrm{~h}$ lower in mixed group 4 h: $P$ 38, PI 37.4, $p=0.05$

5 h: $P$ 37.9, PI 37.1, $p=0.003$

Paul et $a l^{15}$

Diarrhoea, vomiting, rash, cough, cold to

\footnotetext{
Mean temperature at $1-6 \mathrm{~h}{ }^{\circ} \mathbf{C}$ (ta) no difference at $1-3 \mathrm{~h}$, at 4-6 $\mathrm{h}$ lower in mixed (PI) and alternating (IP) than ibuprofen (note order of groups)

4 h: IP 36.9, I 37.5, PI 36.9, $p=0.002$

5 h: IP 36.8, I 38, PI 36.9, p <0.001

6 h: IP 36.9, I 38.5, PI 37.2, p<0.001
}

No differences in renal and liver values and no abnormalities at 14 days touch, admitted to hospital no differences and none considered to be related to study

No side effects prevented administration and did not differ between groups

Did not evaluate effect of multiple doses or adverse events that could occur from this
Repeat dosages needed at 3 and 4 $\mathrm{h}$ no difference

NCCPC score and repeat dosages on days 1-3 lower in mixed group, highest in paracetamol group

No discomfort at $48 \mathrm{~h}$, pairwise comparisons no difference

\section{No data}

a, axilla; I, ibuprofen; GI, gastrointestinal; NCCPC, non-communicating children's pain checklist; 0, oral; P, paracetamol; PI/IP paracetamol and ibuprofen; r, rectal; SGOT, serum glutamic oxaloacetic transaminase; SGPT, serum glutamic pyruvic transaminase; $t$, tympanic; ta, temporal artery. 
on the first day ( $\mathrm{d} 0)$, but the combined treatment was superior on subsequent days. This statistically significant difference is, however, difficult to assess from a clinical perspective. There were few reports of side effects, none of which could be directly attributed to the drugs, and there was no difference between them. However, none of the studies were of sufficient sample size or length to exclude toxicity, and most relied on passive reporting, reducing the sensitivity of the studies to identify toxicity as opposed to side effects.

\section{EXPERT OPINION}

Four official guidelines were searched for evidence of expert opinion about the use of antipyretics in general, and opinion about the use of combinations specifically. ${ }^{4} 1617$ The benefit of this is that it allows the integration of different interpretations of the evidence to be included in the review, although some of these are somewhat dated, and do not include the most recent studies. NICE guidelines state that antipyretics in general should be considered in children who are distressed or unwell, but not with the sole aim of reducing temperature, and not as a combination or alternately as a routine, although these guidelines are currently being updated. The American Academy of Pediatrics recommendations, which are the most recent, being published in 2011, are similar, stating that the primary goal should be that of promoting comfort, and that there is insufficient evidence to support or refute routine use of combination treatment. The Italian Paediatric Society recommendations state that antipyretics should only be used when fever is associated with discomfort, and that combined or alternating use of ibuprofen and paracetamol is not recommended. In the Integrated management of childhood illness manual, which is aimed at developing countries, the World Health Organisation recommends a single dose of paracetamol for what they describe as high fever, which they define as being over $38.5^{\circ} \mathrm{C}$. A search of the European Medicines Agency, Medicines and Healthcare Products Regulatory Authority, and the Federal Drug Administration databases did not reveal any regulatory or safety data on combined or alternating treatments.

\section{DISCUSSION}

Many parents have unfounded fears of fever, ${ }^{1}$ fears that are shared by some healthcare professionals. ${ }^{18}$ Consequently the use of antipyretic drugs is popular, and although both paracetamol and ibuprofen are associated with possible toxicities such as hepatotoxicity ${ }^{19}$, and gastric and antiplatelet effects respectively, ${ }^{20}$ they are generally both safe and effective drugs. ${ }^{21}$ Combining the two drugs for high fever, or fever that does not respond to one drug alone, is not officially recommended, but may be a common practice. ${ }^{3}$ There are a number of concerns about this, in particular possible renal toxicity caused by the additive and possibly synergistic effects of drug metabolites in dehydrated children, ${ }^{22}$ misdosing, and its effect on increasing parental concern about fever. ${ }^{23} 24$ Although some studies did seek to identify side effects, there are few data regarding toxicity, and based on these studies no conclusion can be reached regarding the safety of any treatments. Furthermore, these studies contain no data on children under the age of 6 months.

This review aimed to analyse the major concern of parents, that is fever ${ }^{1}$; the recommendation of official bodies that treatment be aimed at improving comfort 4 17; and the overall concern about possible toxicities and side effects. Because of the methodological heterogeneity it is not possible to statistically integrate the studies; instead they are considered under three headings: the direction of effects; the size of these effects; and the robustness and generalisability of the findings. ${ }^{5}$

Most studies showed some additional reduction in temperature associated with combined or alternating treatment, although this rarely reached clinically or statistically significant levels. Furthermore it is not clear what constitutes the best measure of antipyretic activity. Mean fall in temperature is easy to measure, but it is far from clear that this is of most benefit to the child and family; and the proportion who are afebrile at a given time point or the total time spent without fever might be more relevant.

There were no significant reports of toxicities and side effects in any treatment group, however studies were generally short term, often did not look at this outcome or lacked the power to identify these. Additionally it is often impossible to identify which are the result of the treatment, and which the disease. The limited data also mean that it is difficult to come to any conclusion about comfort because few studies looked at this outcome and those that did used different methods for doing so; indeed it is not clear what constitutes comfort.

The robustness and generalisability of these studies is limited by a number of factors: they are all small studies that lacked power and were too short term, particularly to identify toxicities and side effects; they were often carried out in healthcare facilities which differs from the setting in which antipyretics are often given, thus they study efficacy rather than effectiveness ${ }^{25}$; they used different interventions and methods of recording temperature; many children who might be given antipyretics were excluded from the studies, particularly those at higher risk from toxicities such as those suffering dehydration or comorbidity.

Although there are two distinct approaches within the studies, namely alternating or combining the drugs, there are insufficient data to say that one is superior to the other or to either drug alone in any respect. Because of the heterogeneity of the studies, it is difficult to assess the effect of publication bias, although both positive and negative effects are reported. With these limitations, based on these data there is little evidence to suggest that combining drugs provides much benefit over each drug alone, either in antipyretic efficacy or the promotion of comfort, however there is no evidence of harm either. Despite this, the lack of therapeutic indication for either alternating or combined treatments makes such use of these drugs unwise, even in the absence of data suggesting harm.

\section{CONCLUSION}

From this evidence it appears that there is little benefit from combining paracetamol and ibuprofen, and although there was no evidence of increased toxicity, the studies may have been too small, too short term and excluded children who are most at risk of such toxicities. While it is tempting to conclude that further research should be undertaken, based on the small size and short duration of most existing studies, this is not really necessary. These studies have shown that there is limited benefit from combination treatment; however, this benefit was not immediate. This, alongside the lack of indications for combination therapy, and the ethical and practical difficulties of conducting such research, suggests that resources could be better targeted elsewhere.

This analysis supports the recommendations which suggest that this practice should not be encouraged. In particular, clinicians and parents should note the lack of evidence of increased 
effectiveness either in terms of temperature or comfort; the relative lack of safety data; the effective nature of each drug individually; and the effect that routine co-administration of these drugs might have on increasing parental and professional fever phobia. The emphasis for intervention should therefore be on education of professionals and parents to understand fever; in particular that it is a symptom, and to use resources such as the NICE 'traffic light' system ${ }^{7}$ to treat the underlying condition appropriately.

\section{Competing interests None.}

Provenance and peer review Not commissioned; externally peer reviewed.

\section{REFERENCES}

1. Crocetti M, Moghbeli N, Serwint J. Fever phobia revisited: have parental misconceptions about fever changed in 20 years? Pediatrics 2001;107:1241-6.

2. Purssell E. Parental fever phobia and its evolutionary correlates. J Clin Nurs 2009;18:210-18

3. Wright AD, Liebelt EL. Alternating antipyretics for fever reduction in children: an unfounded practice passed down to parents from pediatricians. Clin Pediatr (Phila) 2007:46:146-50.

4. American Academy of Pediatrics. Fever and antipyretic use in children. Pediatrics 2011;127:580-7.

5. Rodgers M, Sowden A, Petticrew M, et al. Testing methodological guidance on the conduct of narrative synthesis in systematic reviews. Evaluation 2009:15:47-71.

6. Moher D, Liberati A, Tetzlaff J, et al. Preferred reporting items for systematic reviews and meta-analyses: the PRISMA statement. PLoS Med 2009;6:e1000097.

7. National Institute for Health and Clinical Excellence. Feverish illness in children, assessment and initial management in children younger than 5 years. London: National Collaborating Centre for Women's and Children's Health, 2007.

8. Zwarenstein M, Treweek S, Gagnier JJ, et al. Improving the reporting of pragmatic trials: an extension of the CONSORT statement. BMJ 2008;337:a2390.

9. Lal A, Gomber S, Talukdar B. Antipyretic effects of nimesulide, paracetamol and ibuprofen-paracetamol. Indian J Pediatr 2000;67:865-70.
10. Hay AD, Costelloe C, Redmond NM, et al. Paracetamol plus ibuprofen for the treatment of fever in children (PITCH): randomised controlled trial. BMJ 2008:337:a1302.

11. Sarrell EM, Wielunsky E, Cohen HA. Antipyretic treatment in young children with fever: acetaminophen, ibuprofen, or both alternating in a randomized, double-blind study. Arch Pediatr Adolesc Med 2006;160:197-202.

12. Kramer LC, Richards PA, Thompson AM, et al. Alternating antipyretics: antipyretic efficacy of acetaminophen versus acetaminophen alternated with ibuprofen in children. Clin Pediatr (Phila) 2008;47:907-11.

13. Nabulsi MM, Tamim H, Mahfoud Z, et al. Alternating ibuprofen and acetaminophen in the treatment of febrile children: a pilot study [ISRCTN30487061]. BMC Med 2006;4:4.

14. Erlewyn-Lajeunesse MD, Coppens K, Hunt LP, et al. Randomised controlled trial of combined paracetamol and ibuprofen for fever. Arch Dis Child 2006; 91:414-16.

15. Paul IM, Sturgis SA, Yang C, et al. Efficacy of standard doses of ibuprofen alone, alternating, and combined with acetaminophen for the treatment of febrile children. Clin Ther 2010;32:2433-40.

16. World Health Organisation. Handbook IMCl: integrated management of childhood illness, 2000. http://libdoc.who.int/hq/2000/WHO_FCH_CAH_00.12_pp1-82.pdf (accessed 26 May 2011).

17. Chiappini E, Principi N, Longhi R, et al. Management of fever in children: summary of the Italian Pediatric Society guidelines. Clin Ther 2009;31:1826-43.

18. May A, Bauchner H. Fever phobia: the pediatrician's contribution. Pediatrics 1992:90:851-4.

19. Heubi JE, Barbacci MB, Zimmerman HJ. Therapeutic misadventures with acetaminophen: hepatoxicity after multiple doses in children. J Pediatr 1998;132:22-7.

20. Gazarian M, Graudins LV. Safe use of NSAIDs in infants and children. Medicine Today 2006;7:71-3.

21. Goldman RD, Ko K, Linett LJ, et al. Antipyretic efficacy and safety of ibuprofen and acetaminophen in children. Ann Pharmacother 2004;38:146-50.

22. Del Vecchio MT, Sundel ER. Alternating antipyretics: is this an alternative? Pediatrics 2001:108:1236-7.

23. Mofenson HC, McFee R, Caraccio T, et al. Combined antipyretic therapy: another potential source of chronic acetaminophen toxicity. J Pediatr 1998:133:712-14.

24. Mayoral CE, Marino RV, Rosenfeld W, et al. Alternating antipyretics: is this an alternative? Pediatrics 2000;105:1009-12.

25. Haynes B. Can it work? Does it work? Is it worth it? The testing of healthcareinterventions is evolving. BMJ 1999;319:652-3. 